\title{
Pengaruh Kompetensi Pedagogik Dan Profesional Guru Sekolah Menengah Kejuruan Pasca Sertfikasi Terhadap Komitmen Guru Melaksanakan Proses Pembelajaran
}

\author{
Ahyanuardi $^{1^{*}}$ Hambali $^{1}$, Krismadinata ${ }^{1}$ \\ ${ }^{1}$ Jurusan Teknik Elektro, Fakultas Teknik, Universitas Negeri Padang \\ *Corresponding author, e-mail: ahya5216@gmail.com
}

\begin{abstract}
Abstrak- Penelitian ini bertujuan untuk: (1) mengetahui apakah ada pengaruh kompetensi pedagogik dan professional guru SMK pasca sertifikasi terhadap komitmen guru; dan (2) mengetahui berapa besar pengaruh kompetensi pedagogik dan kompetensi professional guru SMK pasca sertifikasi terhadap komitmen guru. Penelitian ini merupakan penelitian deskriptif kuantitatif. Instrumen pengumpulan data menggunakan angket dan analisis data menggunakan teknik regresi berganda. Hasil penelitian menunjukkan bahwa; (1) kompetensi pedagogik dan professional guru SMK pasca sertifikasi memiliki pengaruh yang signifikan terhadap komitmen guru melaksanakan proses pembelajaran; (2) prosentasi komitmen, kompetensi pedagogik dan kompetensi professional guru bersertifikasi, secara rata-rata masih rendah
\end{abstract}

Kata kunci: komitmen, kompetensi pedagogik dan kompetensi profesional

\begin{abstract}
The purpose of this research is : (1) to determine if there is influence of pedagogic and professional competence of SMK teachers to teachers' commitment after certification (2) to determine how much influence of pedagogic and professional competence of SMK teachers to teachers' commitment after certification. This research is a quantative descriptive research. The data collecting instrument used was questionnaire and data analysis used was multiple regression technique. The result showed : (1) there is a significant effect from pedagogic and professional competence of SMK teachers to teachers' commitment in study process after certification (2) the percentage of commitment, pedagogic and professional competence of certified teachers are still low on average.
\end{abstract}

Keywords: commitment, pedagogic competence and professional competence

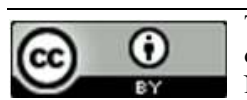

This is an open access article distributed under the Creative Commons 4.0 Attribution License, which permits unrestricted use, distribution, and reproduction in any medium, provided the original work is properly cited. (C2018 by Author and Universitas Negeri Padang

\section{Pendahuluan}

Pendidikan bagian dari kehidupan dan merupakan investasi masa depan suatu bangsa yang bertujuan menghasilkan sumber daya manusia bermutu untuk melaksanakan pembangunan. Pendidikan merupakan kunci utama dalam upaya peningkatan sumber daya manusia [42]. Pendidikan adalah usaha sadar dan terencana untuk mewujudkan suasana belajar dan proses pembelajaran agar peserta didik secara aktif mengembangkan potensi dirinya untuk memiliki kekuatan spiritual keagamaan, pengendalian diri, kepribadian, kecerdasan, akhlak mulia, serta keterampilan yang diperlukan dirinya, masyarakat, bangsa dan negara [40].

Sasaran utama dari pendidikan membentuk kepribadian peserta didik, membina nilai-nilai fundamental, kematangan dan integritas pribadi sehingga mampu bertanggung jawab atas perbuatannya. Hal ini sesuai dengan fungsi pendidikan, yaitu mengembangkan kemampuan dan membentuk watak serta peradaban bangsa yang bermartabat dalam rangka mencerdaskan kehidupan bangsa, bertujuan untuk berkembangnya potensi peserta didik agar menjadi manusia yang beriman dan bertakwa kepada Tuhan Yang Maha Esa, berakhlak mulia, sehat, berilmu, cakap, kreatif, 
mandiri, dan menjadi warga negara yang demokratis serta bertanggung jawab [40].

Salah satu unsur yang sangat esensial dalam bidang pendidikan adalah guru. Dalam proses pendidikan, guru merupakan komponen terpenting karena dianggap mampu memahami, mendalami, melaksanakan, dan mencapai tujuan pendidikan [24]. Hal ini ditegaskan oleh [41] yang menyatakan guru merupakan tenaga profesional yang bertugas merencanakan dan melaksanakan proses pembelajaran, menilai hasil pembelajaran, melakukan pembimbingan dan pelatihan.

Pentingnya guru dalam proses pembelajaran, dibuktikan dengan hasil studi yang dilakukan di negara-negara berkembang oleh [16] yang menemukan bahwa faktor guru memberikan sumbangan dalam prestasi belajar peserta didik sebesaar 36\%. Penelitian [8] mengungkapkan bahwa prestasi belajar peserta didik sangat ditentukan oleh guru, yaitu 34\% pada negara sedang berkembang dan 36\% pada negara industri. Hasil penelitian yang dilakukan oleh [34], juga menunjukkan bahwa kualitas guru merupakan variabel yang sangat penting dalam meningkatkan prestasi belajar peserta didik.

Berbagai usaha telah dilakukan oleh pemerintah untuk meningkatkan dan mengembangkan profesi guru di Indonesia, antara lain melalui program sertifikasi. Tujuan program sertifikasi menurut [23], adalah menentukan mutu dan kelayakan guru dalam melaksanakan tugas sebagai agen pembelajaran dan mewujudkan tujuan pendidikan nasional.

Namun, berdasarkan beberapa hasil penelitian tentang guru bersertifikasi belum menunjukkan hasil seperti yang diharapkan, sehingga tidak berdampak terhadap mutu pendidikan. Berdasarkan hasil penelitian [29], [27], dan [6], menemukan kinerja guru bersertifikasi perlu dipertanyakan. Artinya sertifikasi tidak mempunyai pengaruh yang berarti terhadap peningkatan mutu pendidikan seperti yang diharapkan. Hal ini juga diperkuat oleh [9], yang menyatakan bahwa di Amerika Serikat guru yang memperoleh tunjangan profesi belum menjamin terjadinya peningkatan retensi dan kinerja guru yang bersangkutan.

Salah satu faktor penyebab rendahnya kinerja guru bersertifikat adalah rendahnya komitmen terhadap pekerjaan atau profesi yang digelutinya [1]. Rendahnya kinerja guru dalam melaksanakan tugas dan kewajibannya, dapat dilihat dari 7 (tujuh) indikator sebagai berikut [15]: (1) rendahnya pemahaman tentang strategi pembelajaran; (2) kurangnya kemahiran dalam mengelola kelas; (3) rendahnya kemampuan melakukan dan memanfaatkan penelitian tindakan kelas; (4) rendahnya motivasi berprestasi; (5) kurang disiplin; (6) rendahnya komitmen profesi; dan (7) rendahnya kemampuan manajemen waktu. Dari pernyataan [1] dan [13], secara implisit tersirat bahwa komitmen dipengaruhi oleh kompetensi pedagogik dan profesional yang dikuasai oleh guru. Rendahnya komitmen merupakan indikator bahwa kesetiaan, kesadaran, dan tanggung jawabnya sebagai guru dalam melaksanakan proses pembelajaran perlu di pertanyakan. Komitmen yang rendah terhadap pekerjaan atau profesi yang digelutinya menimbulkan sikap atau perilaku yang tidak positif terhadap pekerjaan atau profesi.

Untuk melaksanakan proses pembelajaran yang efektif dan berkualitas, diperlukan guru profesional yang memiliki kompetensi, menguasai ilmu pengetahuan dan teknologi, memiliki keterampilan dalam mengajar, mempunyai komitmen untuk melaksanakan proses pembelajaran, bertanggung jawab terhadap tugas dan kewajibannya, dan memiliki etika atau moral yang baik. Guru yang memiliki komitmen adalah guru yang setia, sadar, dan bertanggung jawab melaksanakan proses pembelajaran. Dengan kesetiaan, kesadaran dan tanggung jawab tersebut akan menghasilkan suatu proses pembelajaran yang efektif, sehingga dapat mengekplorasi dan mengembangkan potensi peserta didik secara optimal.

Sekolah Menengah Kejuruan (SMK) merupakan lembaga pendidikan kejuruan yang berperan dalam menyiapkan tenaga kerja tingkat menengah, berdasarkan tujuan pendidikan kejuruan yaitu mempersiapkan peserta didik untuk bekerja dalam bidang tertentu [39]. SMK mempunyai muara agar lulusannya memiliki kemampuan, keterampilan, serta ahli dalam di bidang ilmu tertentu dan terampil untuk diaplikasikan ke dunia kerja [4]. Lembaga pendidikan kejuruan, menurut [38], merupakan investasi yang cukup baik dalam mempersiapkan tenaga terampil tingkat menengah.

Hasil observasi awal di SMKN 1Padang, terdapat beberapa hal yang positif dan negatif sebagai indikator kinerja guru pasca sertifikasi dalam proses pembelajaran. Hal-hal yang positif berkaitan dengan proses pembelajaran oleh guru tersertifikasi adalah: (1) kehadiran dan disiplin melaksanakan proses pembelajaran; (2) jumlah guru tersertifikasi sudah banyak; (3) semua guru tersertifikasi sudah 
menyiapkan Rencana Pelaksanaan Pembelajaran (RPP). Sedangkan beberapa hal negatif antara lain: (1) kompetensi pedagogik dan profesional guru dalam melaksanakan proses pembelajaran masih rendah; (2) kinerja guru tersertifikasi perlu ditingkatkan; (3) kesadaran dan tanggung jawab terhadap mutu lulusan masih rendah.

Berdasarkan uraian diatas, belum ditemukan penelitian tentang pengaruh kompetensi pedagogik dan profesional terhadap komitmen guru melaksanakan proses pembelajaran. Oleh sebab itu peneliti tertarik melakukan penelitian tentang pengaruh kompetensi pedagogik dan professional terhadap komitmen guru melaksanakan proses pembelajaran.

Dilandasi oleh latar belakang masalah, rumusan masalah pada penelitian ini adalah: (1) apakah ada pengaruh kompetensi pedagogik dan profesional terhadap komitmen guru melaksanakan proses pembelajaran di SMK pasca sertifikasi dan (2) berapa besar pengaruh kompetensi pedagogik dan profesional terhadap komitmen guru melaksanakan proses pembelajaran di SMK pasca sertifikasi.

Berdasarkan rumusan masalah tersebut, tujuan penelitian yang hendak dicapai adalah: (1) mengungkap pengaruh kompetensi pedagogik dan professional terhadap komitmen guru melaksanakan proses pembelajaran di SMK pasca sertifikasi; dan (2) menghitung berapa besar pengaruh kompetensi pedagogik dan profesional terhadap komitmen guru melaksanakan proses pembelajaran di SMK pasca sertifikasi.

Manfaat yang diharapkan dari penelitian ini adalah: (1) secara teoritis penelitian ini diharapkan memberikan sumbangan pemikiran dalam mengevaluasi komitmen guru SMK pasca sertifikasi; (2) sebagai bahan pertimbangan oleh instansi yang berwenang untuk menentukan kebijakan terkait dengan peningkatan komitmen guru SMK pasca sertifikasi; (3) sebagai masukan dalam penyusunan program pengembangan profesi guru SMK berkelanjutan. Penelitian ini dibatasi pada guru-guru yang telah lulus program sertifikasi, mengajar mata pelajaran bidang studi, dan melaksanakan proses pembelajaran dikelas teori, laboratorium, atau bengkel.

\section{Studi Pustaka}

Sebagai tenaga professional, guru memiliki peran strategis dalam menentukan proses pembelajaran yang efektif dan berkualitas. Dalam proses pembelajaran, guru mentransformasikan ilmu pengetahuan, keterampilan dan seni kepada peserta didik berlangsung [17]. Melalui peran strategis tersebut, diharapkan dapat meningkatkan mutu pendidikan yang tercermin dari hasil belajar peserta didik. Guru merupakan key person untuk menentukan keberhasilan proses pembelajaran [18]. Guru profesional yang kompeten, terampil, dan bertanggung jawab dalam melaksanakan proses pembelajaran dapat meningkatkan mutu pendidikan serta menghasilkan sumber daya manusia yang bermutu [7].

Proses belajar mengajar merupakan kegiatan yang kompleks, oleh sebab itu guru harus menguasai berbagai perspektif dan strategi, serta mampu mengaplikasikannya secara fleksibel [10]. Dalam melaksanakan proses pembelajaran, dibutuhkan dua hal yaitu: (1) profesionalisme, dan (2) komitmen [35]. Pendapat ini didukung oleh [37], yang menyatakan bahwa guru professional harus didukung oleh tiga hal, yaitu: (1) keahlian; (2) komitmen; (3) dan keterampilan.

Guru profesionalis memiliki 4 (empat) kompetensi dasar, yaitu (1) kompetensi pedagogik; (2) kompetensi professional; (3) kompetensi kepribadian; dan (4) kompetensi sosial [27]. Dengan memiliki ke-4 kompetensi dasar tersebut, proses pembelajaran yang dilaksanakan menjadi lebih efektif dan tujuan pembelajaran dapat tercapai secara optimal.

Kompetensi adalah karakteristik dasar individu untuk melakukan suatu profesi pekerjaan sesuai dengan kriteria yang telah ditetapkan dan merupakan kombinasi antara pengetahuan, keterampilan, pemahaman, sikap, keinginan, dan tindakan yang dilakukan [36], [31]. Sedangkan menurut [21], kompetensi adalah seperangkat tindakan cerdas, penuh tanggungjawab yang dimiliki seseorang sebagai syarat untuk dianggap mampu oleh masyarakat dalam melaksanakan tugas-tugas di bidang pekerjaan tertentu.

Komitmen menurut [20], merupakan kesetiaan seseorang untuk berkorban dan mencurahkan semua energi yang dimilikinya terhadap sebuah oraganisasi. Komitmen merupakan keterikatan dan kebersamaan secara psikologis antar individu dan organisasi untuk mencapai tujuan organisasi [16], [24], [2], [22], dan [21]. Hubungan psikologis seseorang terhadap pekerjaan tersebut dapat memberikan gambaran tentang perilaku kerja seseorang dalam bekerja untuk mencapai tujuan. Dengan kata lain, komitmen adalah janji pada diri sendiri atau pada orang lain yang tercermin dalam tindakan. Orang yang memiliki komitmen terhadap pekerjaannya akan berusaha untuk melakukan kewajiban dan tugas pekerjaan serta mempertahankan keterlibatan dalam pekerjaan tersebut [30]. 
Komitmen dalam bidang pendidikan adalah janji untuk setia, sadar, dan bertanggung jawab sebagai guru melaksanakan proses pembelajaran yang efektif dan berkualitas berdasarkan kompetensi yang dimilikinya. Dengan kesetiaan, kesadaran, dan tanggung jawab sebagai pendidik, seorang guru mampu memperbaiki dan meningkatkan kualitas proses pembelajaran yang berdampak pada peningkatan mutu pendidikan secara nasional.

Berdasarkan kajian teoritis tersebut dapat digambarkan hubungan antara kompetensi pedagogik dan profesional dengan komitmen sebagai berikut.

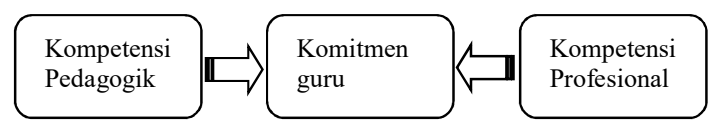

Gambar1. Hubungan Kompetensi Pedagogik dan Profesional dengan Komitmen

\section{Metode}

Penelitian melibatkan 390 responden lulusan D3 Fakultas Teknik Universitas Negeri Padang dan Politeknik Negeri Padang.

\section{Jenis Penelitian}

Penelitian menggunakan metode deskriptif kuantitatif. Penelitian deskriptif untuk menggambarkan objek atau subjek yang diteliti sesuai apa adanya secara sistematis, berdasarkan fakta dan karakteristik objek yang diteliti secara tepat. Penelitian kuantitatif adalah penelitian yang sistematis terhadap bagian-bagian dan fenomena serta hubungan-hubungannya.

\section{Waktu dan Tempat Penelitian}

Pada penelitian ini dilaksanakan dari bulan September sampai dengan bulan November 2017. Penelitian dilakukan di SMKN 1 Padang, SMKN 5 Padang, dan SMKN 1 Sumbar.

\section{Subjek Penelitian}

Subjek penenlitian ini adalah guru-guru yang mengajar mata pelajaran bidang studi, baik di kelas teori, laboratorium, atau bengkel yang telah lulus sertifikasi dan siswa.

\section{Prosedur Penelitian}

Langkah-langkah penelitian sebagai berikut: (1) penelitian pendahuluan dan pengumpulan informasi; (2) penyusunan model kaitan antar variabel; (3) uji validitas model melalui expert judgment dan revisi; (4) penyusunan instrument penelitian; (5) uji coba instrument penelitian; (6) pengumpulan data penelitian; (7) pengolahan dan analisis data penelitian; dan (8) penulisan laporan akhir.

Kisi-kisi instrumen penelitian dikembangkan berdasarkan variabel-variabel penelitian. Kisi-kisi instrumen dari masingmasing variabel seperti pada tabel 1 .

Tabel 1. Kisi-kisi Instrumen Penelitian

\begin{tabular}{|c|c|}
\hline Variabel & Indikator \\
\hline \multirow{3}{*}{$\begin{array}{l}\text { 1. Komitmen } \\
\text { guru (Y) }\end{array}$} & a. Setia sebagai pendidik \\
\hline & b. Sadar sebagai pendidik \\
\hline & $\begin{array}{l}\text { c. tanggung jawab sebagai } \\
\text { pendidik }\end{array}$ \\
\hline \multirow[t]{3}{*}{$\begin{array}{l}\text { 2. Kompetensi } \\
\text { Pedagogik }\left(\mathrm{X}_{1}\right)\end{array}$} & $\begin{array}{l}\text { a. perencanaan proses } \\
\text { pembelajaarn }\end{array}$ \\
\hline & $\begin{array}{l}\text { b. pelaksanaan proses } \\
\text { pembelajaran }\end{array}$ \\
\hline & $\begin{array}{l}\text { c. evaluasi proses } \\
\text { pembelajaran }\end{array}$ \\
\hline \multirow{3}{*}{$\begin{array}{l}\text { 3. Kompetensi } \\
\text { Professional }\left(\mathrm{X}_{2}\right)\end{array}$} & a. penguasaan materi ajar \\
\hline & $\begin{array}{l}\text { b. penguasaan strategi } \\
\text { pembelajaran }\end{array}$ \\
\hline & $\begin{array}{l}\text { c. kaitan konten dengan } \\
\text { konteks }\end{array}$ \\
\hline
\end{tabular}

\section{Teknik Analisis Data}

Analisis pada penelititan ini terdiri dari dua bagian, yaitu analisis tentang instrumen penelitian dan analisis tentang pengaruh antar variabel seperti model yang ditentukan. Analisis instrumen meliputi validitas dan reabilitas. Sedangkan analisis pengaruh antar variabel menggunakan teknik regresi berganda.

\section{Validitas instrumen}

Pengujian karakteristik item dilakukan sebelum melakukan estimasi terhadap reliabilitas dan validitas, yang berfungsi untuk mengetahui kualitas item-item sebuah instrumen. Item-item yang memenuhi persyaratan digunakan pada analisis reliabilitas dan validitas. Sedangkan item-item yang tidak memenuhi persyaratan diikutkan pada analisis reliabilitas dan validitas [32]. Fungsi pengukuran item adalah memperlihatkan kesesuaian antara fungsi item dengan fungsi tes secara keseruluhan. Pengujian kesesuaian fungsi item dengan fungsi ukur tes dihitung mengunakan koefisien 
korelasi item-total. Formula koefisien korelasi butir-total terkoreksi [33] sebagai berikut.

$$
\begin{aligned}
& r_{i(x-i)}=\frac{\left(r_{i x} S_{x}-S_{i}\right)}{\sqrt{\left(S_{x}^{2}+S_{i}^{2}-2 r_{i x} S_{i} S_{x}\right)}} \\
& \boldsymbol{r}_{\boldsymbol{i}(x-\boldsymbol{i})}=\text { Koefisien korelasi skor item-total } \\
& \text { terkoreksi } \\
& \boldsymbol{r}_{\boldsymbol{i x}}=\text { Koefisien korelasi skor item-total } \\
& \text { sebelum dikoreksi } \\
& \boldsymbol{S}_{\boldsymbol{i}}=\text { Deviasi standar skor item yang } \\
& \text { bersangkutan } \\
& \boldsymbol{S}_{\boldsymbol{x}}=\text { Deviasi standar skor tes }
\end{aligned}
$$

\section{Reabilitas Instrumen}

Reliabilitas instrumen penelitian dihitung menggunakan formula KuderRichardson-20 sebagai berikut [31]

$$
\mathrm{KR}-20=[\mathrm{k}(\mathrm{k}-1)]\left[\mathrm{L}-\Sigma \mathrm{p}(1-\mathrm{p}) / \mathrm{S}_{\mathrm{x}}^{2}\right] .
$$

$\mathrm{KR}-20=$ koefisien reliabilitas instrumen

$\mathrm{S}_{\mathrm{x}}^{2}=$ varians skor tes

$\mathrm{p}=$ proporsi subjek yang mendapat 1

pada suatu item

$k$ = banyaknya item dalam tes

Nilai reliabilitas instrumen yang diharapkan adalah 0,70 atau lebih.

\section{Analisis Regresi Berganda}

Analisis regresi berganda digunakan untuk menelaah hubungan antara dua variabel atau lebih, atau untuk mengetahui bagaimana variasi dari bberapa variabel independen mempengaruhi variabl dependen. Persamaan regresi berganda yang digunakan sebagai berikut:

$$
\begin{aligned}
& \mathrm{Y}=\mathrm{a}+\mathrm{b}_{1} \mathrm{X}_{1}+\mathrm{b}_{2} \mathrm{X}_{2} \\
& b_{1}=\frac{\left(\sum \mathrm{x}_{2}^{2}\right)\left(\sum \mathrm{x}_{1} \mathrm{y}\right)-\left(\sum \mathrm{x}_{1} \mathrm{x}_{2}\right)\left(\sum \mathrm{x}_{2} \mathrm{y}\right)}{\left(\sum \mathrm{x}_{1}^{2}\right)\left(\sum \mathrm{x}_{2}^{2}\right)-\left(\sum \mathrm{x}_{1} \mathrm{x}_{2}\right)^{2}} \\
& \mathrm{~b}_{2}=\frac{\left(\sum \mathrm{x}_{1}^{2}\right)\left(\sum \mathrm{x}_{1} \mathrm{y}\right)-\left(\sum \mathrm{x}_{1} \mathrm{x}_{2}\right)\left(\sum \mathrm{x}_{2} \mathrm{y}\right)}{\left(\sum \mathrm{x}_{1}^{2}\right)\left(\sum \mathrm{x}_{2}^{2}\right)-\left(\sum \mathrm{x}_{1} \mathrm{x}_{2}\right)^{2}} \\
& \mathrm{a}=\frac{\sum \mathrm{y}}{\mathrm{n}}-\mathrm{b}_{1}\left(\frac{\sum \mathrm{x}_{1}}{\mathrm{n}}\right)-\mathrm{b}_{2}\left(\frac{\sum \mathrm{x}_{2}}{\mathrm{n}}\right) \text {. }
\end{aligned}
$$

\section{Statistik Deskriptif}

Analisis hasil pengukuran dilakukan secara deskriptif dan kategorisasi data hasil pengukuran dengan kriteria berdasarkan skala yang digunakan. Pada penelitian ini menggunakan empat skala, sehingga kriteria hasil pengukuran dikategorikan dalam empat kategori [22] yaitu

Kategori sangat tinggi dengan kriteria

$$
\mathrm{X} \geq \overline{\mathrm{X}}+1 . \mathrm{SB}_{\mathrm{X}}
$$

Kategori tinggi dengan kriteria

$$
\overline{\mathrm{X}}+1 . \mathrm{SB}_{\mathrm{X}}>\mathrm{X} \geq \overline{\mathrm{X}}
$$

Kategori rendah dengan kriteria

$$
\overline{\mathrm{X}}>\mathrm{X} \geq \overline{\mathrm{X}}-1 . \mathrm{SB}_{\mathrm{X}}
$$

Kategori sangat rendah dengan kriteria

$$
\mathrm{X}<\overline{\mathrm{X}}-1 . \mathrm{SB}_{\mathrm{X}}
$$

Keterangan:

$\overline{\mathrm{X}}=$ rerata skor

$\mathrm{SB}_{\mathrm{X}}=$ simpangan baku skor

$\mathrm{X}=$ skor yang dicapai

\section{HASIl DAN PEMbahasan}

\section{Validitas Instrumen}

Hasil analisis instrumen komitmen guru, kompetensi pedagogik guru, dan kompetensi profesional guru, menunjukkan bahwa hampir semua item instrumen mempunyai koefisien korelasi item-total terkoreksi $\geq 0,3$ dan hanya beberapa item saja yang mempunyai nilai koefisien korelasi item-total terkoreksi $<0,3$. Item-item dengan nilai koefisien korelasi toralitem terkoreksi $<0,3$, diperbaiki struktur kalimatnya, sehingga dapat dipergunakan dalam penelitian.

\section{Reabilitas Instrumen}

Instrumen komitmen guru memiliki reabilitas sebesar 0,881 , instrumen kompetensi pedagogik guru memiliki nilai reabilitas sebesar 0,884, dan instrumen kompetensi profesional guru mempunyai nilai reabilitas sebesar 0,926. Dengan demikian dapat dikatakan bahwa semua instrumen memiliki tingkat kepercayaan yang tinggi dan dapat dipergunakan dalam penenlitian ini. 


\section{Hasil Analisis Regresi}

Analisis regresi menggunakan software SPPP sebagai alat bantu. Dari hasil analisis diperoleh nilai-nilai coefisien parameterparameter $a, b_{1}$, dan $b_{2}$ seperti pada tabel sebagai berikut:

Tabel 2. Coefficients parameter regresi

\begin{tabular}{|l|r|r|r|r|r|}
\hline \multirow{2}{*}{ Model } & \multicolumn{2}{|c|}{$\begin{array}{c}\text { Unstandardized } \\
\text { Coefficients }\end{array}$} & $\begin{array}{c}\text { Standardized } \\
\text { Coefficients }\end{array}$ & \multirow{2}{*}{} & \multirow{2}{*}{ Sig. } \\
\cline { 2 - 5 } & \multicolumn{1}{|c|}{ B } & Std. Error & \multicolumn{1}{|c|}{ Beta } & \multicolumn{1}{|c|}{$\mathrm{T}$} & Sig \\
\hline 1 (Constant) & 3.449 & .783 & & 4.405 & .000 \\
PED & .394 & .070 & .360 & 5.625 & .000 \\
PRO & .230 & .070 & .211 & 3.303 & .001 \\
\hline
\end{tabular}

a. Dependent Variable: KOM

Berdasarkan tabel 2 tersebut diperoleh persamaan regresinya sebagai berikut:

$\mathrm{Y}=3.449+0.394 \mathrm{X}_{1}+0.230 \mathrm{X}_{2}$

Dari persamaan regresi tersebut ternyata kemampuan kompetensi pedagogik dan professional guru memiliki pengaruh yang berarti terhadap komitmen guru dalam melaksanakan proses pembelajaran. Hal ini sesuai dengan pendapat [1] dan [13], komitmen dipengaruhi oleh kompetensi pedagogik dan profesional

\section{Statistik Deskriptif}

Tabel 3. Kategori variabel Komitmen Guru

\begin{tabular}{lc}
\hline \multicolumn{1}{c}{ Kategori } & Persentase \\
\hline \hline Sangat Tinggi & 1.23 \\
\hline Tinggi & 59.26 \\
\hline Rendah & 37.04 \\
\hline Sangat Rendah & 2.47 \\
\hline \hline \multicolumn{1}{c}{ Total } & 100,00 \\
\hline \hline
\end{tabular}

Hasil uji, menunjukkan 60,49\% guru memiliki komitmen dengan kategori tinggi dalam melaksanakan proses pembelajaran. Hal ini mengindikasikan bahwa guru yang lulus sertifikasi memiliki kesetiaan, kesadaran, tanggung jawab dalam melaksanakan proses pembelajaran untuk mencapai tujuan pendidikan secara nasional.
Tabel 4. Kategori variabel kompetensi pedagogik

\begin{tabular}{lc}
\hline \hline \multicolumn{1}{c}{ Kategori } & Persentase \\
\hline \hline Sangat Tinggi & 3.71 \\
\hline Tinggi & 54.12 \\
\hline Rendah & 34.07 \\
\hline Sangat Rendah & 8.10 \\
\hline \hline & 100,00 \\
\hline \hline
\end{tabular}

Jumlah guru yang telah lulus sertifikasi memiliki kompetensi pedagogik dengan kategori tinggi sebesar 57,83\%. Kompetensi pedagogik merupakan salah satu kompetensi dasar yang berfungsi untuk merencanakan, melaksanakan, dan mengevaluasi proses pembelajaran. Kompetensi pedagogik yang rendah mengakibatkan perencanaan, pelaksanaan dan evaluasi proses pembelajaran tidak berjalan seperti yang diinginkan. Hal ini akan berdampak terhadap perkembangan peserta didik.

Tabel 5. Kategori variabel Kompetensi Profesional Guru

\begin{tabular}{lc}
\hline \hline \multicolumn{1}{c}{ Kategori } & Persentase \\
\hline \hline Sangat Tinggi & 3.98 \\
\hline Tinggi & 50.00 \\
\hline Rendah & 37.91 \\
\hline Sangat Rendah & 8.10 \\
\hline \hline & 100,00 \\
\hline \hline
\end{tabular}

Kompetensi profesional menekankan kepada penguasaan materi ajar, penguasaan strategi pembelajaran, dan mengkaitkan antara konten dengan konteks. Guru bersertifikasi yang memiliki kemampuan kompetensi professional dengan kategori hanya 53,98\%. Artinya bahwa guru dapat menyampaikan materi pembelajaran dengan baik dan efektif, karena guru sendiri menguasai tentang materi tersebut dan memahami tentang strategi untuk menyampaikan materi ajar tersebut. Dengan demikian tujuan pembelajaran yang ditetapkan akan tercapai dan pemahaman peserta didik tentang tentang materi ajar menjadi bekal untuk memasuki dunia kerja. 


\section{KESIMPULAN}

Dari hasil penelitian tentang pengaruh kompetensi pedagogik, professional guru SMK pasca sertifikasi dan komitmen terhadap guru melaksanakan proses pembelajaran, dapat disimpulkan sebagai berikut:

1. Model hubungan antar variabel berdasarkan pernyataan validator dinyatakan valid dan sesuai dengan teori yang digunakan.

2. Instrument penelitian berdasarkan hasil analisis validitas dan reabilitas dinyatakan valid dan reliable, sehingga dapat digunakan dalam proses penelitian.

3. Kompetensi pedagogik dan professional mempunyai pengaruh yang signifikan terhadap komitmen guru melaksanakan proses pembelajaran.

4. Prosentasi guru bersertifikat memiliki komitmen, kompetensi pedagogik dan professional secara rata-rata masih rendah.

Berdasarkan hasil temuan penelitian, disarankan kepada pengambil kebijakan:

1. Melakukan peningkatan kompetensi pedagogik, professional, dan komitmen guru melaksanakan proses pembelajaran, sehingga dapat meingkatkan mutu proses pembelajaran dan berdampak terhadap mutu pendidikan.

2. Menambahkan variabel lain dalam penelitian ini yang diperkirakan mempunyai pengaruh terhadap komitmen guru dalam melaksanakan proses pembelajaran.

\section{DAfTAR PUSTAKa}

[1] Abdullah Solichan. (2012). Nilai Komitmen Guru Pada Tugas.

[2] Allen, N.J. \& Meyer, J.P. (1994) Organiszational Commitment.

[3] Arnie Fajar. (2006). Peranan Sertifikasi Guru dalam Meningkatkan Profesionalisme Guru. Makalah Seminar Nasional Sosialisasi Sertifikasi Guru dalam memaknai UU No. 14 Tahun 2005. Sisdik Jawa Barat, Bandung.

[4] Arif Firdaus \& Barnawi. (2012). Profil Guru SMK Profesional. Yogyakarta, Ar-Ruzz Media.
[5] Azeem, S.M (2010). Job Satisfaction and Organizational Commitment among Employees in the Sultanate of Oman. Psychology, 2010, 1, 295-299.

[6] Baedhowi (2008). Strategi Peningkatan Kualitas dan kompetensi Guru. Diraktorat Jenderal Peningkaan Mutu Pendidikan dan Tenaga Kependidikan Departemen Pendidikan Nasional. Surabaya

[7] Barnawi \& Mohammad Arifin. (2012). Kinerja Guru Profesional. Jogjakarta: Penerbitt Ar-Ruzz Media.

[8] Dedi Supriadi. (1998). Mengangkat Citra dan Martabat Guru. Yogyakarta: Adicita Karya Nusantara.

[9] Dee, T \& Wyckoff, J. (2013). Incentives, Selection, and Teacher Performance: Evidence from IMPACT. NBER Working Paper No. 19529 October 2013 JEL No. I2, J45.

[10] Diaz, C. (1997). Unpublished Review of J.W. Santrock's Educational Psychology. New York :Mc-Graw-Hill.

[11] Dixit, V \& Bhakti, M (2012). A Study about Employee Commitment and its impact on Sustained Productivity in Indian autoComponent Industry. Eupean Journal of Business and Social Sciences, Vol. 1, No. 6, pp 34-51.

[12] Djemari Mardapi. (2012). Pengukuran, Penilaian dan Evaluasi Pendidikan. Yogyakarta: NUHA Medikan.

[13] E. Mulyasa. (2005). Menjadi Guru Profesional. Menciptakan Pembelajaran Kreatif dan Menyenangkan. Bandung: Rosdakarya

[15] Hall, D.T., Schneider, B., \& Nygren, H.T (1970). Personal factors in organizational identification. Administrative Science Quarterly, 15, 176-189.

[16] Indra Djati Sidi. (2000). Pendidikan dan Peran Guru Dalam Era Glabalisasi. Majalah Komunikasi, No. 25/Tahun VII/2000.

[17] Iskandar Agung. (2012). Menghasilkan Guru Kompeten dan Profesional. Jakarta: Penerbit Bee Media Indonesia.

[18] Jones, J., Jenkin, M., \& Lord S. (2006). Developing effective teacher performance. London: Paul Chapman Publishing.

[19] Kanter, R (2001). Evolve. Harvard Business School Press. Boston

[20] Keputusan Menteri Pendidikan Nasional Nomor 045/u/2002 Tentang kurikulum Inti Pendidikan Tinggi.

[21] Lee, T.W., Ashford, S.J., Walsh, J.P. \& Mowday, R.T.(2000). Commitment Propensity, Organizational Commitment and Voluntary Turnover: a Longitudinal Study of Organizational Entry Processes. Journal of Managememnt, Vol. 18, No. 1, 15-32.

[22] Meyer \& Allen (1997). Commitment in the workplace, Theory, research and application. Thousand Oaks, CA: Sage. 
[23] Mowday, Richard. R.T., Steers, R.M. \& Porter, L.W (1979). The measurement of organizational.

[24] Muchlas Samani. (2006). Sertifikasi Guru di Indonesia. Surabaya: SIC.

[25] Muhammad Nurdin. (2008). Kiat Menjadi Guru Profesional. Yogyakarta: Arruz.

[26] Mungin Eddy Wibowo. (2004). Standarisasi, Sertifikasi, dan Lisensi Profesi Pendidik dan Tenaga Kependidikan. Surabaya: Seminar Nasional Pendidikan.

[27] Nyanyu Khodijah. (2010). Kinerja Guru Pasca Sertifikasi (Studi Terhadap Kinerja Guru Madrasah dan Guru PAIS Pada Sekolah Umum di Propinsi Sumatera Selatan.

[28] Peraturan Pemerintah Republik Indonesia Nomor 19 Tahun 2005 Tentang Standar Nasional Pendidikan.

[29] Ridwan El Hariri. (2010). Dampak Sertifikasi Terhadap Kinerja Guru di Jawa Barat. Universitas Pendidikan Indonesia Bandung.

[30] Rosita Endang Kusmaryani. (2007). Membudayakan Nilai-Nilai Komitmen Terhadap Pekerjaan Dalam Upaya Menegakkan Etika Profesi. Dinamika Pendidikan No. 1/Th. XIV/Mei 2007. Hal 90-101

[31] Ruth, D.C (2008). Key Competencies for Education in a European Context: narratives of accountability or care. European Educational Research Journal Volume $7 N^{\circ} 32008$.

[32] Saifuddin Azwar (2013). Sikap Manusia Teori dan Pengukurannya, Edisi 2. Pustaka Pelajar. Yogyakarta.

[33] Saifuddin Azwar. (2013). Tes Prestasi Fungsi dan Pengembangan Pengukuran Prestasi Belajar. Edisi 2. Pustaka Pelajar. Yogyakarta.

[34] Sanders, W.L. \& Horn, S.P. (1998). Reseach Findings from the Tennessee Value-Added Assessment System (TVAAS) Database: Implication for Educational Evaluation and Research. Journal of Personnel Evaluation in Education, 12(3), 247-256.

[35] Santrock J.W., (2011). Psikologi Pendidikan. (Terjemahan Tri Wibowo B.S). new York: McGraw-Hill Company, Inc. (Buku asli diterbitkan tahun 2004).

[36] Spencer, L.M.Jr., \& Spencer, S.M (1993). Competence At Work, Model For Superior Performance. John Wiley \& Sons, Inc. New York.

[37] Suharsimi Arikunto. (1990). Manajemen Pengajaran Secara Manusiawi. Jakarta: Rineka Cipta.

[38] Sukamto (1988). Perencanaan dan pengembangan kurikulum pendidikan teknologi dan kejuruan. Jakarta: Direktorat Jenderal Pendidikan Tinggi Depdikbud.

[39] Sukamto. (1998). Orientasi dunia kerja dalam proses dan status akreditasi SMK. Jurnal Kependidikan Edisi Khusus Dies Tahun XXXVIII. Hal. 109-126.
[40] Undang-Undang Republik Indonesia Nomor 20 Tahun 2003 Tentang Sistem Pendidikan Nasional.

[41] Utami, Athika Dwi Wiji Utami. (2012). FaktorFaktor Determinan Profesionalisme Guru SMK Bidang Keahlian Teknologi Informasi dan Komunikasi. Jurnal Pendidikan Vokasi. Vol. 2, No. 2, hal 169-182.

[42] Wardan Suyanto. (2005). Pendidikan Menengah Kejuruan Dengan Kurikulum Berbasis Kompetensi. Jurnal Pendidikan dan Teknologi, Volume 14, Nomor 1, Mei 2005.

\section{Biodata Penulis}

Ahyanuardi, dilahirkan di Padang, 5 Januari 1959. Menyelesaikan S1 pada Jurusan Pendidikan Teknik Elektro FPTK IKIP Padang tahun 1983. Tahun 1999 memperoleh gelar Magister Teknik Elektro di Institut Teknolig Bandung, dan memperoleh gelar Doktor Pendidikan Teknologi Kejuruan tahun 2016 di Universitas Negeri Yogyakarta. Sejak tahun 1985 menjadi staf pengajar tetap di JurusanTeknik Elektro Fakultas Teknik Universitas Negeri Padang.

Hambali, dilahirkan di Bukittinggi, 8 Mei 1962. Menyelesaikan pendidikan S1 pada Jurusan Pendidikan Teknik Elektro FPTK IKIP Padang tahun 1987. Gelar Master Kesehatan diperoleh pada tahun 2005 dari Universitas Gajah Mada Yogyakarta. Sejak tahun 1987 sampai sekarang menjadi staf pengajar tetap di Jurusan Teknik Elektro Fakultas Teknik Universitas Negeri Padang.

Krismadinata, lahir di Padang, 11 September 1977. Menyelesaiakan studi S1 di Universitas Andalas, S2 di Institut Teknologi Bandung, dan S3 di Universitas Malaya. Dosen di Jurusan Teknik Elektro Fakultas Teknik Universitas Negeri Padang sejak tahun 2000-sekarang. 